\title{
Fugitive dust from agricultural land affecting air quality within the Columbia Plateau, USA
}

\author{
B. S. Sharratt \\ USDA Agricultural Research Service, Pullman, Washington, USA
}

\begin{abstract}
Windblown dust originating from agricultural land has contributed to poor air quality within the Columbia Plateau region of the Pacific Northwest United States. In fact, the United States Environmental Protection Agency (US EPA) national ambient air quality standard for PM10 (particulates $\leq 10 \mu \mathrm{m}$ in diameter) is exceeded each year in the Columbia Plateau due to fugitive dust emitted from agricultural land. Winter wheat - summer fallow is the conventional crop rotation employed on $>1.5$ million ha within the region. During the 13-month summer fallow period, multiple tillage operations are performed to conserve soil water and control weeds; these tillage operations also create erosive soil conditions due to burial of crop residue and degradation of soil aggregates. Instrumentation was installed to measure sediment flux and PM10 concentration at the windward and leeward positions in fields maintained in summer fallow. Soil loss resulting from singular high wind events ranged from 0 to $2317 \mathrm{~kg} / \mathrm{ha}$ over a four-year observation period. The corresponding loss of PM10 during these high wind events ranged from 0 to $212 \mathrm{~kg} / \mathrm{ha}$. For those events with measurable soil loss, PM10 comprised 5 to $12 \%$ of the total soil loss. Although loss of PM10 during high wind events is relatively small compared to total soil loss, such quantities are sufficient to degrade air quality. In fact, under atmospheric conditions, which accompany high wind events within the Columbia Plateau, a loss of only $5 \mathrm{~kg} / \mathrm{ha}$ of PM10 from all agricultural land in summer fallow is sufficient to raise ambient PM10 concentration above the US EPA standard. Therefore, alternative tillage or cropping practices are sought for reducing the loss of topsoil and PM10 from fields managed in summer fallow during high wind events.
\end{abstract}

Keywords: PM10, wind erosion, fugitive dust, agriculture, particulate matter, high winds, dust storms, windblown dust. 


\section{Introduction}

Fine soil particles emitted into the atmosphere during high winds have contributed to the exceedance of the United States Environmental Protection Agency (US EPA) national ambient air quality standard for PM10 (particulate matter $\leq 10 \mu \mathrm{m}$ in diameter) in the western US. In fact, PM10 emitted from agricultural land has been a major contributor to poor air quality within the Columbia Plateau region of the Pacific Northwest (Sharratt and Lauer [1]) where the 24-h PM10 standard $(150 \mu \mathrm{g} / \mathrm{m} 3)$ is exceeded on average twice annually (fig. 1). The semiarid climate, occasional high winds, fragile and fine-textured soils, and large extent of land managed in a conventional winter wheat - summer fallow rotation ( $>1.5$ million ha) promotes wind erosion that contributes toward poor air quality within the region.

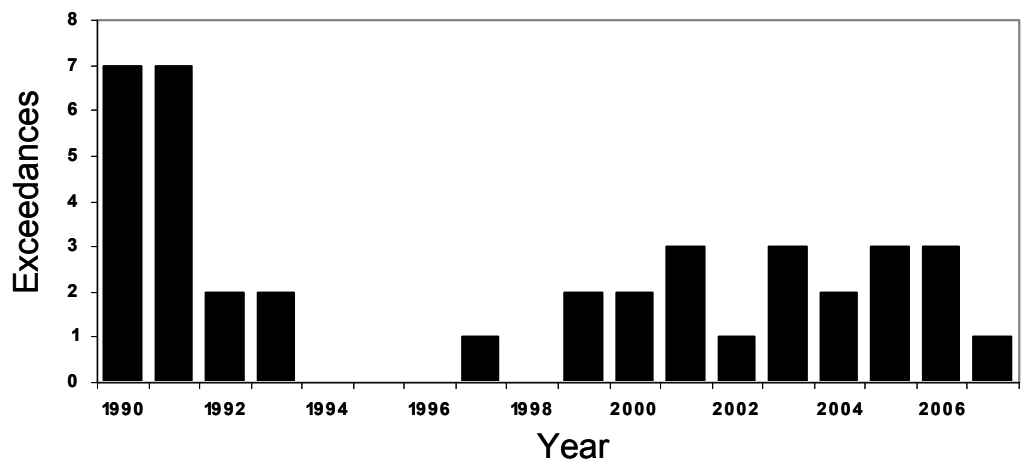

Figure 1: $\quad$ Number of days the US EPA 24-hour PM10 air quality standard was exceeded from 1990-2007 at Kennewick, Washington, USA.

Wind erosion and air quality studies conducted in the Columbia Plateau region over the past decade have focused on ascertaining the magnitude of soil and PM10 transport across agricultural landscapes (Kjelgaard et al [2]) and developing a model capable of simulating horizontal sediment flux and emission of PM10 from soils (Saxton et al [3]). The wind erosion and PM10 emission model developed by Saxton et al [3] attempts to predict vertical PM10 flux as a function of the estimated horizontal sediment transport. Although the aim of these previous studies was to ascertain horizontal sediment transport and vertical PM10 flux from large fields managed primarily in a winter wheat - summer fallow rotation, the experimental design lacked the rigor to assess the loss of soil and PM10 from agricultural fields.

Farm conservation programs such as the United States Department of Agriculture (USDA) Conservation Reserve Program are designed to conserve soil resources and to protect air and water resources. In an effort to conserve soil resources, quantitative data are needed regarding soil loss from farm land because biomass production cannot be sustained where the rate of soil erosion exceeds the rate of soil regeneration. To protect air resources, quantitative data are needed regarding PM10 loss from farm land because loss of fine particulates 
to the atmosphere must not jeopardize attainment of PM air quality standards. Future farm conservation programs will likely regulate the loss of PM10 from agricultural fields. In fact, the USDA is currently seeking information about tolerable limits of PM10 loss from agricultural fields to protect air quality during high winds within the Columbia Plateau. This study attempts to determine the loss of PM10 from agricultural fields during high winds and implications of PM10 loss on regional air quality.

\section{Field campaigns}

Soil erosion and loss of PM10 were assessed from agricultural fields located within the Columbia Plateau of the Pacific Northwest United States (fig. 2). Soils within the Columbia Plateau were formed from loessial deposits. Wind erosion is particularly acute in areas with $<300 \mathrm{~mm}$ of annual precipitation and where winter wheat-summer fallow is the predominate dryland cropping system. This cropping system is typified by a 13-month fallow period that begins after harvest of wheat in July. Soils are typically cultivated on numerous occasions during the fallow period to control weeds and conserve soil water.

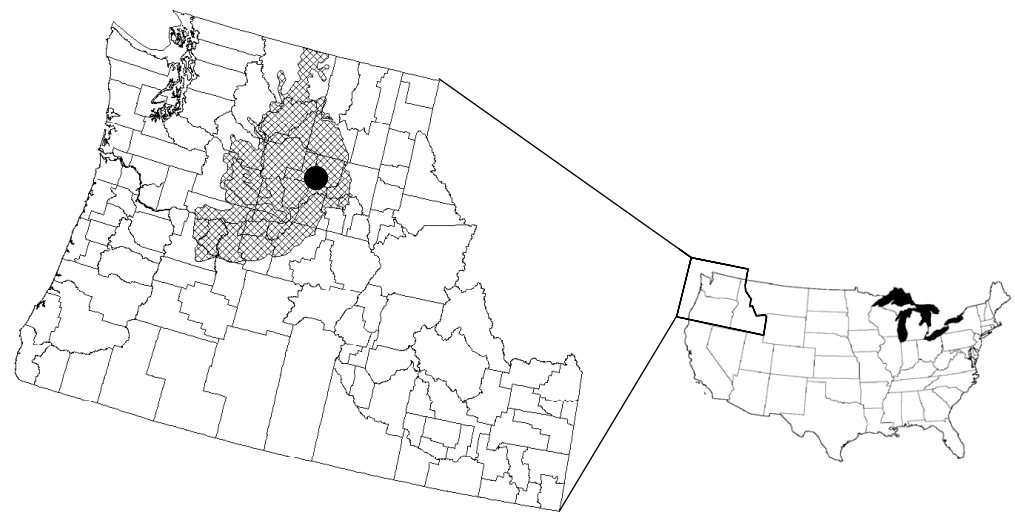

Figure 2: $\quad$ Location of field sites (dot) within Columbia Plateau (shaded area) of the Pacific Northwest United States.

Loss of soil and PM10 was assessed from 2003 to 2006 at field sites (2 to 9 ha) maintained in summer fallow. Soils at the field sites were classified as silt loam with a geometric mean particle diameter of 25 to $35 \mu \mathrm{m}$. A nonerodible surface was maintained upwind (south and west) of the sites. Each field site was managed by the cooperator using conventional tillage practices which included disking in the spring after wheat harvest and then rod-weeding at monthly intervals prior to sowing winter wheat in late August. PM10 samplers and creep and saltating/suspended sediment collectors were deployed at the windward and leeward positions in the field to respectively assess the influx and efflux of PM10 and soil. PM10 samplers were mounted at three heights above the soil 
surface and activated when the wind speed exceeded $6.4 \mathrm{~m} / \mathrm{s}$ at a height of $3 \mathrm{~m}$ for 10 consecutive minutes. This threshold, designated as a high wind event, is that required to initiate movement of soils across the Columbia Plateau [3]. Filters for the PM10 samplers were equilibrated to standard laboratory conditions before and after deployment. Six sets of saltating/suspended sediment collectors (Big Spring Number Eight or BSNE collectors) were deployed in the field with each set consisting of 5 BSNE collectors mounted on a pole at heights from 0.1 to $1.5 \mathrm{~m}$. Collection of field data was periodic due to the remoteness of the field sites and generally occurred immediately after a high wind event or series of high wind events with persistent SW winds. An instrumented field site is portrayed in fig. 3 .

Total horizontal soil flux at the windward and leeward positions in the field was equivalent to the sum of creep and BSNE catch. The vertical distribution of saltating/suspended sediment captured by the BSNE collectors was described using the equation:

$$
\mathrm{q}=\mathrm{az}^{-\mathrm{b}}
$$

where $\mathrm{q}$ is sediment catch $\left(\mathrm{kg} / \mathrm{m}^{2}\right), \mathrm{z}$ is height $(\mathrm{m})$ of the opening of the BSNE collector above the soil surface, and $\mathrm{a}$ and $\mathrm{b}$ are fitted parameters (Zobeck and Fryrear [4]). Saltating and suspended sediment flux was then determined by integrating eqn. (1) from 0.025 to $5 \mathrm{~m}$ (approximate height where integrated flux for all high wind events approached maximum value). Net soil loss from the field for each high wind event was calculated as the difference between total horizontal soil flux at the leeward and windward positions in the field.

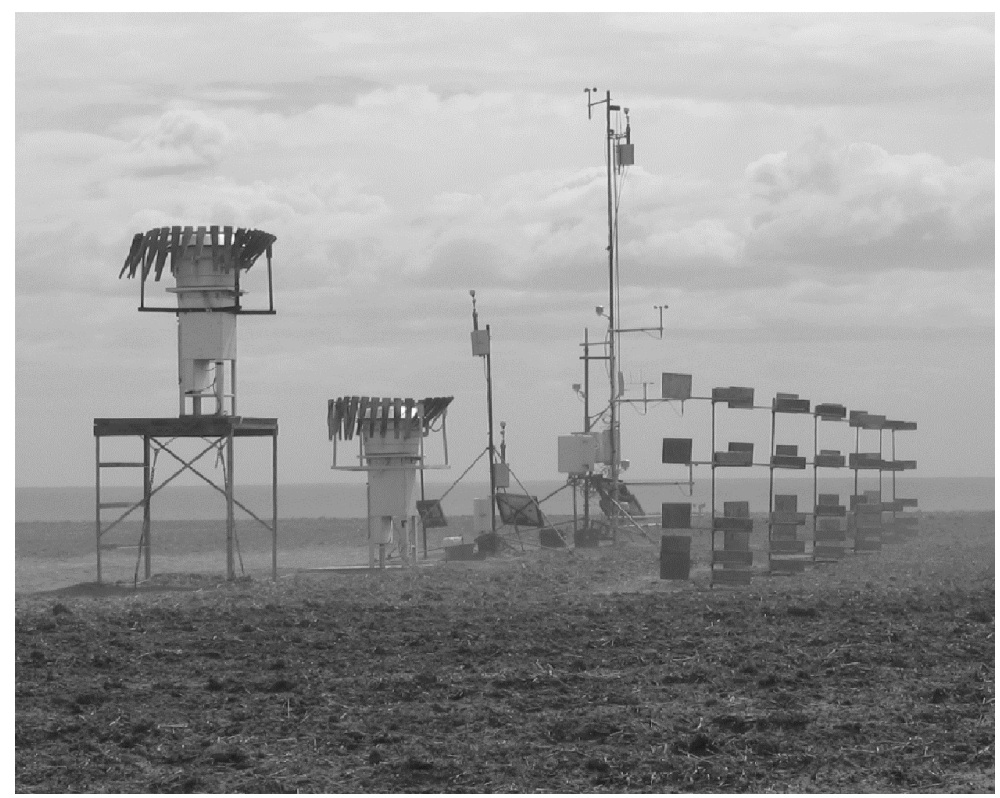

Figure 3: $\quad$ Instrumentation to measure soil and PM10 loss from a field during summer fallow within the Columbia Plateau. 
Loss of PM10 from the field site was assessed for each high wind event by subtracting horizontal PM10 flux at the windward position from that at the leeward position in the field. Horizontal PM10 flux (PM10 $0_{\mathrm{hf}}$ ) at the windward and leeward field positions was determined by:

$$
\mathrm{PM} \mathrm{O}_{\mathrm{hf}}=\int \mathrm{C}_{\mathrm{z}} \mathrm{u}_{\mathrm{z}} \mathrm{tdz}
$$

where PM10 $0_{\mathrm{hf}}$ is in $\mu \mathrm{g} / \mathrm{m}, \mathrm{C}_{\mathrm{z}}$ is PM10 concentration at height $\mathrm{z}, \mathrm{u}_{z}$ is wind velocity at height $z$, and $\mathrm{t}$ is the duration of an event. The integral was evaluated from $0.025 \mathrm{~m}$ to the height of the PM10 plume. The PM10 concentration profile was obtained from BSNE catch and PM10 samplers. PM10 concentration based upon BSNE catch was derived from PM10 mass in the BSNE collector and volume of air moving through the BSNE collector during a high wind event. Plume height was obtained by extrapolating the PM10 concentration profiles at the windward and leeward positions in the field.

\section{Observed soil and PM10 loss}

Over the four years of this study, soil and PM10 loss from field sites in summer fallow was assessed for 12 high wind events. These events were characterized by persistent SW winds whereby a nonerodible boundary was maintained upwind of the field site for the duration of the event. No erosion or PM10 loss occurred during two high wind events (23 Jun -8 Jul 2005 and 19-25 Jul 2006) because of the presence of a crust on the soil surface during these events. Characteristics of high wind events during which soil and PM10 loss was observed are reported in Table 1. PM10 loss comprised from 5 to $12 \%$ of total soil loss.

Table 1: Characteristics of high wind events observed between sample dates from 2003 to 2006 within the Columbia Plateau, USA.

\begin{tabular}{|l|l|l|l|l|l|}
\hline Year & Sample period & Time & $\begin{array}{l}\text { Maximum 3-m } \\
\text { wind speed } \\
(\mathrm{m} / \mathrm{s})\end{array}$ & $\begin{array}{l}\text { Soil } \\
\text { loss } \\
(\mathrm{kg} / \mathrm{ha})\end{array}$ & $\begin{array}{l}\text { PM10 } \\
\text { loss } \\
(\mathrm{kg} / \mathrm{ha})\end{array}$ \\
\hline 2003 & 12-22 Sep & 26 & 12.5 & 43 & 5 \\
\hline & $3-15$ Oct & 47 & 14.4 & 118 & 10 \\
\hline & $15-27$ Oct & 41 & 11.9 & 44 & 5 \\
\hline & $27-29$ Oct & 14 & 17.6 & 2317 & 212 \\
\hline 2004 & $6-23$ Aug & 20 & 10.3 & 138 & 16 \\
\hline & 23 Aug -9 Sep & 43 & 10.7 & 1604 & 163 \\
\hline 2005 & 31 Aug -14 Sep & 24 & 13.0 & 120 & 7 \\
\hline 2006 & $14-19$ Jul & 11 & 9.3 & 29 & 2 \\
\hline & 29-30 Aug & 17 & 12.0 & 401 & 50 \\
\hline & 30 Aug -6 Sep & 11 & 11.6 & 258 & 17 \\
\hline
\end{tabular}

The maximum PM10 concentration (based upon 10 minute averages) observed at a height of $5 \mathrm{~m}$ equalled $8535 \mu \mathrm{g} / \mathrm{m}^{3}$ and occurred during the 27-29 
October 2003 high wind event. The mean 5-m PM10 concentration during this 14-hour event was $790 \mu \mathrm{g} / \mathrm{m}^{3}$.

\section{Implication of PM10 loss for air quality}

Loss of PM10 from agricultural land influences air quality within the Columbia Plateau. To better understand the impact of fugitive dust emissions from agricultural fields on regional air quality, the Columbia Plateau Wind Erosion / Air Quality Project (http://pnw-winderosion.wsu.edu/) has supported the development of a regional air quality model. Although a regional air quality model has been developed for the Project and tested with varying degrees of success (Sundram et al [5]), the model is based upon a highly empirical wind erosion and PM10 emission algorithm. Current efforts are now underway to incorporate the Wind Erosion Prediction System or WEPS (WEPS is a processed based wind erosion model as described by Hagen [6]) into the Air Information Report for Public Access and Community Tracking or AIRPACT (AIRPACT can be accessed online at http://lar.wsu.edu/airpact-3/introduction.html) system to better understand PM10 emissions and atmospheric transport processes within the Columbia Plateau.

For the purpose of this paper, we present an analytical approach to determining the impact of fugitive dust emissions on regional air quality. The importance of PM10 loss observed over the four years of this study on air quality can be illustrated by considering a field with dimensions of $100 \times 100 \mathrm{~m}$ that is maintained in summer fallow. Also assume that PM10 emissions occur from the field on a day when winds of $8 \mathrm{~m} / \mathrm{s}$ are sustained for 10 hours (Stetler and Saxtion [7]), PM10 is emitted into an affected area (cross-sectional length of 100 $\mathrm{m}$ ) immediately downwind of the field and uniformly mixes to a height of $400 \mathrm{~m}$ within the atmospheric boundary layer (Claiborn et al [8]), and winds are calm prior to and following the high wind event. Based upon these field and atmospheric characteristics, emission of $5 \mathrm{~kg}$ PM10 during the high wind event will effectively increase atmospheric PM10 concentration by $0.43 \mu \mathrm{g} / \mathrm{m}^{3}$ within the affected area. Thus, the atmospheric PM10 concentration would exceed the US EPA national ambient air quality standard of $150 \mu \mathrm{g} / \mathrm{m}^{3}$ when $>348$ fields (>348 ha) immediately upwind of the affected area are each emitting $5 \mathrm{~kg}$ PM10 during the event. Similarly, the national ambient air quality standard for PM10 would be exceeded when $>9$ fields ( $>9$ ha) immediately upwind of the affected area are each emitting $200 \mathrm{~kg}$ PM10 during the event. Furthermore, assume that regional storms with predominately SW winds affect PM10 concentrations across a $200 \mathrm{~km}$ swath of the Columbia Plateau (Claiborn et al [8]). Based upon the lateral dimension of regional storms, PM10 concentrations within the affected area would exceed the national ambient air quality standard when $>0.7$ million ha immediately upwind of the affected area are emitting $5 \mathrm{~kg}$ PM10/ha or when $>17300$ ha upwind of the affected area are emitting $200 \mathrm{~kg}$ PM10/ha. Although nearly 0.7 million ha are maintained in summer fallow in any given year, the latter case would represent about $2 \%$ of all fields in summer fallow within the Columbia Plateau. Therefore, regional air quality can be compromised 
even during seemingly small events when all land in summer fallow is emitting PM10.

\section{Controlling fugitive dust emissions to improve air quality}

A close linkage exists between wind erosion and fugitive dust emissions from agricultural lands. Thus, fugitive dust emissions can be suppressed by implementing practices that control wind erosion. A volume of literature exists that describes methods for controlling wind erosion (Nordstrom and Hotta [9])). These methods attempt to enhance cover of nonerodible material (e.g. straw) on the soil surface, roughen the soil surface using tillage implements, and decrease the fetch by using barriers such as tall wheatgrass. Nonerodible materials, however, have little application in the low precipitation zone of the Columbia Plateau where the economic plight of farming in this region precludes additional input costs associated with applying nonerodible material to the soil surface. In addition, the extent of land managed by a single farmer and the non-uniformity in size of farm machinery poses challenges in using wind barriers.

The low precipitation zone of the Columbia Plateau has an annual precipitation of $<0.3 \mathrm{~m}$; about $70 \%$ of this is received during winter (October March). These precipitation characteristics necessitate maintaining the land in fallow every other year. For the past 120 years, farmers have used "dust mulch" tillage to conserve soil water during summer fallow. This type of tillage results in a layer of finely dispersed soil particles that is about $0.1 \mathrm{~m}$ deep. The "dust mulch" layer is effective in creating an enriched zone of moisture at a depth of $0.1 \mathrm{~m}$ (seed depth) when winter wheat is sown in late August. This enriched zone of moisture allows wheat to germinate and emerge through otherwise parched top soil; any delay in sowing past August will reduce yield.

Recent efforts to control wind erosion within the Columbia Plateau have focused on annual cropping systems. Annual crops protect the soil surface during the growing season, but these cropping systems lack the economic and productive stability of the conventional wheat-fallow crop system (Schillinger et al [10]). Reduced tillage systems have attained some success (Schillinger [11]); these systems protect the soil surface by retaining crop residue or nonerodible aggregates on the soil surface. Recently, the USDA Natural Resource Conservation Service has promoted the use of an undercutter tillage implement to reduce wind erosion and fugitive dust emissions (Burnham [12]). While conventional tillage implements (e,g, plow, disk) partially or completely invert the soil during primary tillage, the undercutter implement creates little soil disturbance due to the low pitch of the wide V-blades on the tool bar (fig. 4). Currently, the undercutter tillage implement is being evaluated as a wind erosion control method in the field. Measurements of soil and PM10 loss to date indicate that fugitive dust emissions during high wind events can be reduced by 30 to $70 \%$ using the undercutter versus the conventional disk implement during primary tillage. 


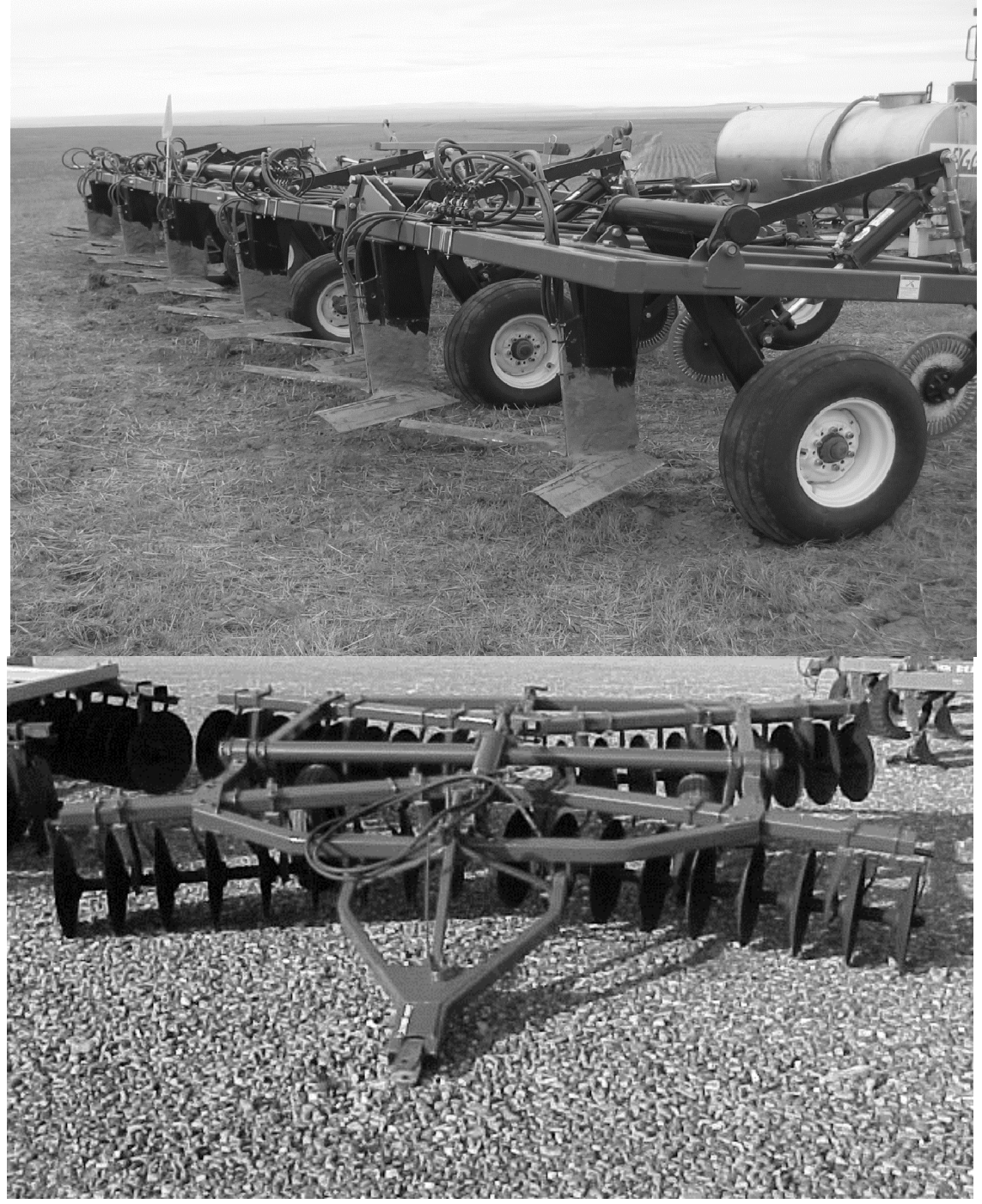

Figure 4: The top image is an undercutter tillage implement with $0.8-\mathrm{m}$ wide $\mathrm{V}$-blades and the bottom image is a conventional disk implement.

\section{References}

[1] Sharratt, B.S. \& Lauer, D., Particulate matter concentration and air quality affected by windblown dust in the Columbia Plateau, Journal of Environmental Quality, 35, pp. 2011-2016, 2006.

[2] Kjelgaard, J., Sharratt, B., Sundram, I., Lamb, B., Claiborn, C. \& Saxton, K., PM10 emission from agricultural soils on the Columbia Plateau: 
comparison of dynamic and time-integrated field-scale measurements and entrainment mechanisms, Agricultural and Forest Meteorology, 125, pp. 259-277, 2004.

[3] Saxton, K., Chandler, D., Stetler, L., Lamb, B., Claiborn, C. \& Lee, B., Wind erosion and fugitive dust fluxes on agricultural lands in the Pacific Northwest, Transactions of the American Society of Agricultural Engineers, 43, pp. 623-630, 2000.

[4] Zobeck, T.M. \& Fryrear, D.W., Chemical and physical characteristics of windblown sediment I. Quantities and physical characteristics, Transactions of the American Society of Agricultural Engineers, 29, pp. 1032-1036, 1986.

[5] Sundram, I., Claiborn, C., Strand, T., Lamb, B., Chandler, D. \& Saxton, K., Numerical modeling of windblown dust in the Pacific Northwest with improved meteorology and dust emission models, Journal of Geophysical Research, 109, D24208, doi:10.1029/2004JD004794, 2004.

[6] Hagen, L.J., A wind erosion prediction system to meet user needs, Journal of Soil and Water Conservation, 46, pp. 106-111, 1991.

[7] Stetler, L.D. \& Saxton, K.E., Wind erosion and PM10 emissions from agricultural fields on the Columbia Plateau, Earth Surface Processes and Landforms, 21, pp. 673-685, 1996.

[8] Claiborn, C., Lamb, B., Miller, A., Beseda, J., Clode, B., Vaughan, J., Kang, L. \& Newvine, C., Regional measurements and modeling of windblown agricultural dust: the Columbia Plateau PM10 program. Journal of Geophysical Research, 103, pp. 19753-19767, 1998.

[9] Nordstrom, K.F. \& Hotta, S., Wind erosion from cropland in the USA: a review of problems, solutions and prospects, Geoderma, 121, pp. 157-167, 2004.

[10] Schillinger, W.F., Kennedy, A.C. \& Young, D.L., Eight years of annual no-till cropping in Washington's winter wheat - summer fallow region, Agriculture, Ecosystems and Environments, 120, pp. 345-358, 2007.

[11] Schillinger, W.F., Minimum and delayed conservation tillage for wheatfallow farming, Soil Science Society of America Journal, 65, pp. 1203 1209, 2001.

[12] Burnham, T.J., Study finds savings in using undercutter, Western Farmer Stockman, May issue, p. 6, 2007. 